\title{
The Effect of Overload on Crack Growth Behaviour in Biaxial Fatigue
}

\author{
Mehdi Mokhtarishirazabad*, Pablo Lopez-Crespo, Belen Moreno \\ Department of Civil and Materials Engineering, University of Malaga, C/Dr Ortiz Ramos s/n, 29071, Malaga, Spain
}

\begin{abstract}
This paper focus on the study of biaxial fatigue cracks based on a methodology that enables evaluation of the overload effect in fatigue. The methodology is based on the experimental evaluation via full-field technique of digital image correlation of the effective stress intensity factor and the crack opening displacement (COD). The tests were performed on cylindrical specimens made of low carbon steel subjected to tension-tension and a combination of tension and torsion loads. The experimental data was used to compare the crack growth behaviour with an overload cycle under uniaxial and biaxial loading. A hybrid method was also employed to evaluate the value of the Stress Intensity Factor (SIF) before and after applying the overload. The results showed a reliable estimation of closure level and SIF for both uniaxial and biaxial loading condition. A new procedure previously developed for uniaxial loads was adapted to the study of biaxial loads. This new procedure was used to identify important differences produced by the overload event.
\end{abstract}

\footnotetext{
*Corresponding author: mokhtari@uma.es
}

\section{Introduction}

Stress intensity factor is known as one of the most important fracture parameters for characterising the crack behaviour in the engineering components. Since 1957 when Irwin [1] formulized the stress intensity factor, a considerable works have been done to improve our understanding on its importance in crack growth behaviour under static and cyclic loading [2,3]. Finite element method had been employed widely during last decades for detailed analysis of the crack tip fields (stress, strain, displacement) to evaluate the SIF and phenomenon such as crack closure [4-6]. In addition, some mathematical models have been introduced describing the crack tip field such as Westergaard's [7], Williams' [8], and recently CJP [9] models. Different techniques have been developed to obtain an full-field measurement of the crack tip field, experimentally, such as Moire interferometry [6], photo-elasticity[10], thermos-elasticity[11], and digital image correlation (DIC) [12].

Among these techniques, DIC is widely using due to a number of advantageous such as being easy to implement, easy sample preparation, and being a scalefree method. The latter one means that it can measure on the scale ranging from a few meters [13] to micro-meters $[14,15]$. Measured displacement data by DIC can be fitted to one of abovementioned models using Multipoint over-deterministic method [16] to estimate the most important fracture parameters of the material such as SIF[12,17-19].
Many structures in real applications are often subjected to a mixed mode loading rather pure mode I of loading [20,21]. Therefore, considering the mixed-mode loading in the evaluation of SIF will be more representative of the material fracture behaviour under the actual working condition. Yoneyama et al [22], evaluated the mixed mode SIFs of polymethylmethacrylate by post-processing the displacement field derived by DIC method. A method based on the Lagrangian conservation law for mixed-mode SIFs estimations used by Réthoré et al [23] to estimate the SIFs using the concept of virtual crack extension and auxiliary field. Lopez-Crespo et al. [24] fitted Muskhilishvili's model to the displacement data derived by DIC to evaluate the SIFs in a sample made of Al 7010 alloy under mode I and mixed mode (I+II) loading. They reported a good agreement between nominal and experimental evaluation of SIFs.

In addition, many engineering components are subjected to variable amplitude loads. To estimate the fatigue life of these components, it is essential to quantify the crack growth rate which is, in turn, affected by the plastic deformation at the crack tip. To consider the effect of external load variation on crack growth rate, usually the effects of a single overload are examined $[25,26]$. Nowell et al. [6] employed the moire interferometry and DIC to determine the presence of crack closure in propagating fatigue crack by examining the measured in-plane displacement around the crack tip. They used a similar method used previously by de Matos [27] to monitor the displacement of some pairs of points close to the crack tip for determining the closure level. 
DIC also used by Yusof et al. [28] to determine the closure load using crack opening displacement (COD) and evaluated SIF. They used Muskhilishvili's model to evaluate the experimental SIF. Others have conducted experimental and numerical investigation on the effect of an overload cycle on fatigue crack growth under mixed mode loading [29-31]. Nevertheless, there are very little knowledge, if any, about the application of optical methods to study the effect of overload cycle on the crack growth rate under tension-tension (uniaxial) and tension-torsion (biaxial) cyclic loading is available. Recently, the author has conducted an experiment to study the influence a single overload cycle on the closure level and fatigue crack growth rate in hollow cylinder samples under in-phase tension-torsion loading [32]. In the present work, DIC is employed to evaluate the crack closure and mixed mode SIFs for samples under tensiontension and tension-torsion loading.

\section{Materials and Methods}

Experiments are conducted on a low carbon steel (St 52$3 \mathrm{~N})$. Due to its good weldability and high ductility of this alloy, this alloy is oftenused in offshore platforms and marine structures. Table 1 shows the chemical composition of the material. The mechanical behaviour of the alloy is showed in Table 2. This material combines very good fatigue properties with low environmental impact for non-transport applications [33].

Microstructural of the alloy consists of ferrite and pearlite bands as vertical white and black bands, respectively (Fig.1). Fig. 2 illustrates a schematic of the geometry of the sample.

Table 1. Chemical composition of St 52-3N alloy

\begin{tabular}{|l|l|l|l|l|l|l|l|}
\hline $\mathrm{C}$ & $\mathrm{Si}$ & $\mathrm{Mn}$ & $\mathrm{P}$ & $\mathrm{S}$ & $\mathrm{Cr}$ & $\mathrm{Ni}$ & $\mathrm{Mo}$ \\
\hline 0.17 & 0.22 & 1.23 & 0.01 & $>0.0001$ & 0.07 & 0.06 & 0.16 \\
\hline
\end{tabular}

Table 2. Monotonic properties of St-52-3N steel

\begin{tabular}{|l|l|}
\hline Yield stress, $\sigma_{\mathrm{y}}$ & $386 \mathrm{MPa}$ \\
\hline Ultimate tensile stress, $\sigma_{\mathrm{u}}$ & $639 \mathrm{MPa}$ \\
\hline Young's modulus, E & $206 \mathrm{GPa}$ \\
\hline Shear Modulus & $78 \mathrm{GPa}$ \\
\hline
\end{tabular}

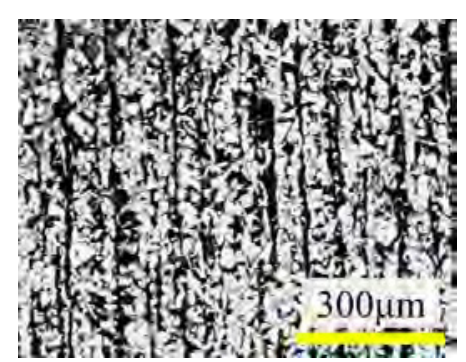

Fig. 1. The microstructure of St52-3N steel. Black and white vertical bands are showing the pearlite and ferrite bands, respectively [34].

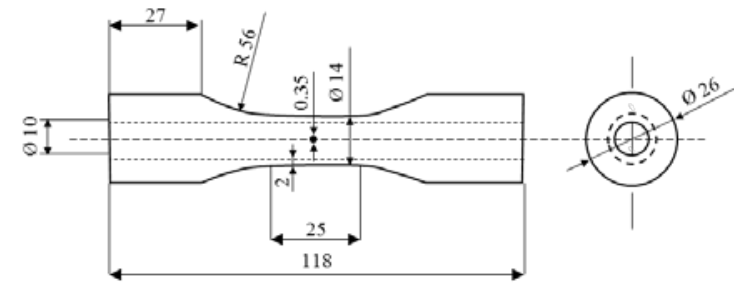

Fig. 2. The geometry of the hollow cylinder specimen with a central hole. All dimensions are in $\mathrm{mm}$.

Axial and biaxial loads under stress control mode were conducted by a MTS 809 servo-hydraulic loading rig coupled by a biaxial extensometer Epsilon 3550 . Uniaxial tension-tension cyclic loading test was conducted on Sample1 with sinus signal and axial load ratio of $0.1\left(\mathrm{R}_{\mathrm{a}}=0.1\right)$, while an in-phase torsional load with load ratio of $-1\left(R_{t}=-1\right)$ superimposed to the axial loadings on Sample2 for the biaxial loading case. The range of axial load was 0.56 of the yielding strength of the alloy. Fig. 3 shows the loading path for Sample2. To enforce the crack to nucleate inside the field of view, a through hole with a diameter of 0.378 and $0.432 \mathrm{~mm}$ was drilled in the outer surface of the Sample1 and Smaple2, respectively. A zero-offset in the number of cycles was applied when the crack length was 0.638 and $0.430 \mathrm{~mm}$ for Sample1 and Sample2, respectively. It should mention that crack length determined by adding the radius of hole to the length of the crack from the crack initiation point at the circumference of the hole to the crack tip in one side of the hole. Visual inspection, showed an equal crack length at both sides of the hole.

In order to study the effect of the overload on the crack propagation behaviour, a $40 \%$ overload was applied on both samples when the crack length was 0.99 $\mathrm{mm}$ in Sample1 and $0.796 \mathrm{~mm}$ in Sample2. That is, the load range in the overload cycle was 1.4 times larger than load range during the rest of the test. The cyclic loading then continued until the crack length reached 1.5 $\mathrm{mm}$. Table 3 shows the nominal value of applied loads for both samples. The crack length was evaluated from the crack-tip position with optical microscopy. The related average error in measuring the crack growth rate was $0.002 \mu \mathrm{m} /$ cycle. The incremental polynominal technique as recommended in ASTM E647-15 [35] was employed to examine the cyclic crack growth rate. Table 3 shows the loading condition for both samples.

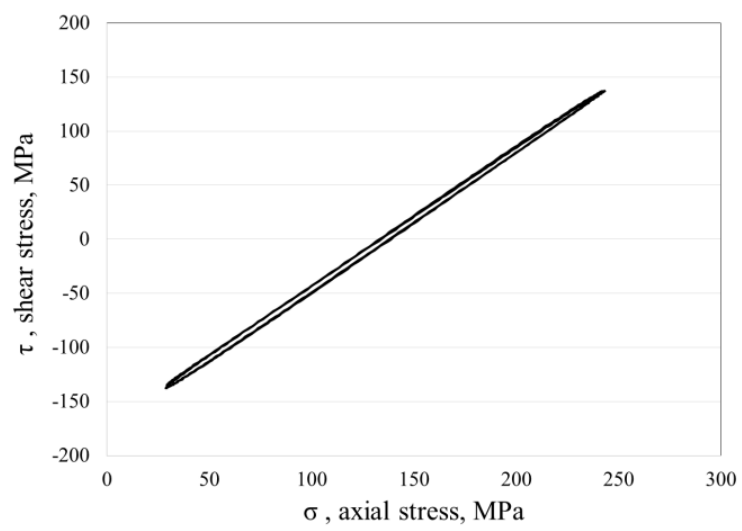


Fig. 3. Loading path for Sample2.

Table 3. Axial and shear stress values for specimens with and without overload cycle.

\begin{tabular}{|l|c|c|c|c|c|}
\hline Sample1 & 0.99 & 216 & 277 & - & - \\
\hline Sample2 & 0.79 & 216 & 277 & 302.4 & 388 \\
\hline
\end{tabular}

\begin{tabular}{|l|l|l|l|l|l|}
\hline \multirow{2}{*}{ Specimen } & $\begin{array}{l}\text { Crack length } \\
\text { at OL, } \mu \mathrm{m}\end{array}$ & $\Delta \sigma$ & $\Delta \tau$ & $\Delta \sigma_{\mathrm{OL}}$ & $\Delta \tau_{\mathrm{OL}}$ \\
& $\mathrm{MPa}$ & $\mathrm{MPa}$ & $\mathrm{MPa}$ & $\mathrm{MPa}$ \\
\hline
\end{tabular}

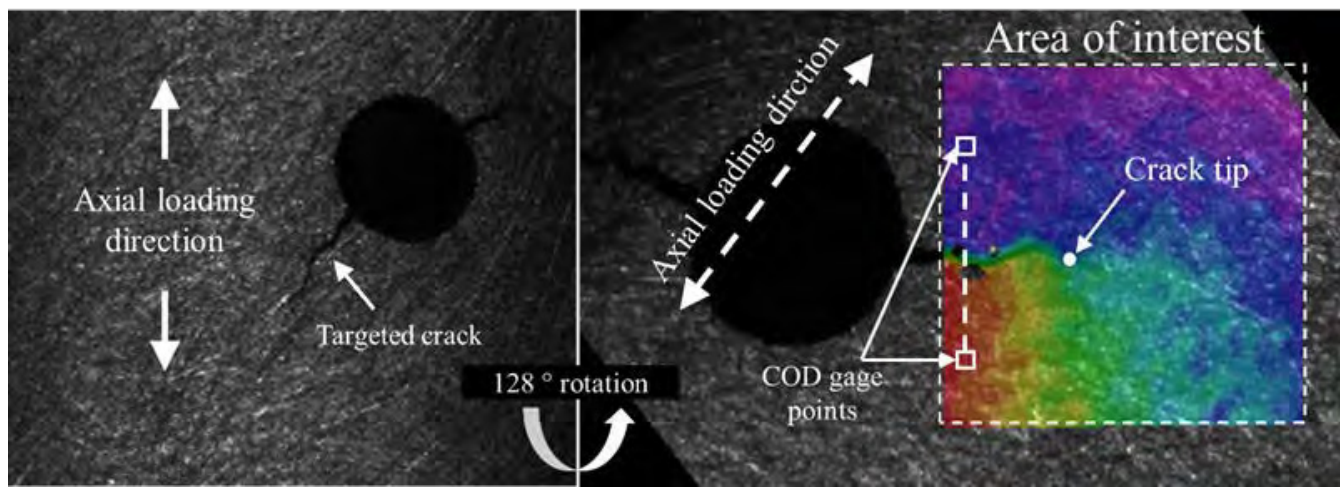

Fig. 4. The field of view of the Sample2 and the vertical displacement contour around the crack tip derived by DIC. The image is rotated 128 degree counter clockwise to obtain a horizontal crack line. The position of COD gage points is illustrated.

Crack tip displacement fields were captured during cyclic loading with a 5 MP CCD camera coupled with a macro Navitar lens and adaptor tube which provided a field of view $(\mathrm{FOV})$ was $3.55 \times 2.97 \mathrm{~mm}^{2}$. The contrast required for DIC technique was introduced by finely abrading the surface so that the bare crack tip region is imaged directly [36] This allowed faster and easier positioning of the crack tip [37]. In this way, a resolution of 1.45 micron per pixel was obtained. To take sufficient number of images, the loading frequency was reduced to $0.3 \mathrm{~Hz}$ to take 75 images during a complete cycle. Obtained images processed by VIC 2D V6 software [38].Recommendations given in [39] were followed to improve the quality of the SIF estimations. Accordingly, a high order interpolation scheme of optimized 8-tap spline was used for DIC analysis to achieve sub-pixel accuracy. The subset size was adjusted to $39 \times 39$ pixels. In addition, just $25 \%$ of the crack line was considered in the area of interest (the area where the displacement data were measured by DIC). The relative error in the estimated displacement (and consequently in COD) was $2.95 \%$. This relative error was estimated from the quality of the correlation of the images taken at different loads. By taking to account the size of the area of interest $(0.8$ $\times 0.8 \mathrm{~mm}^{2}$ ), two terms in the Williams' solution were used as suggested in [39]. Since the crack propagation direction for Sample2 was $50 \pm 3^{\circ}$, to extract the vertical and the horizontal displacements with respect the axial loading axis, captured images have been rotated so that the crack appears horizontal in all images. Fig. 4 illustrates the vertical displacement contour for an area of interest around a crack with a length of $0.55 \mathrm{~mm}$ (Sample2).

To monitor the behaviour of the left-side crack, the images were rotated $128^{\circ}$ counter clockwise so that the crack line was horizontal. Displacement data points inside an area of $0.8 \times 0.8 \mathrm{~mm}^{2}$ were extracted and fitted to Williams' solution in order to calculate SIFs.
In order to determine the presence of crack closure, crack opening displacement (COD) was measured by DIC at $0.3 \mathrm{~mm}$ behind the crack tip as follows:

$$
C O D=\sqrt{u_{x \text { bot }}^{2}-u_{y \text { bot }}^{2}}-\sqrt{u_{x \text { top }}^{2}-u_{y \text { top }}^{2}}
$$

where $u_{x}$ and $u_{y}$ are the horizontal and vertical displacement respectively. The subscripts "top" and "bot" refer to the position of the virtual extensometer points relative to the crack line. These points are shown in Fig. 4. In order to improve the quality of presented COD data, the Fourier series with 1 and 3 terms was fitted to the loading signal and COD data, respectively.

To estimate the SIFs, derived displacement data by DIC were fitted into Williams' series using the multipoint over-deterministic method. For the sake of brevity, the related equations and details of the method are not presented here. It has been explained in details in our previous work [32]. SIF in mode I and mode II then reported for various crack lengths before and after overload for both uniaxial and biaxial loading condition.

\section{Results and Discussion}

\subsection{Fatigue Crack Growth Rate}

Fig. 5 shows the evolution of crack growth before and after applying a $40 \%$ overload on Sample1 and Sample2 under uniaxial and biaxial loading, respectively. There are two main difference between the crack behaviour under uniaxial and biaxial loading regime. First, the post-overload crack growth of Sample1 (Fig.5.a) consists a delayed retardation stage, while it is not appreciable for Sample2 (Fig. 5.c) under biaxial loading. Such delay in retardation has been observed in our previous study for biaxial loading only when the range of baseline axial and shear stress was $25 \%$ and $17 \%$ lower than thereof for Sample2 [32]. Secondly, crack growth rate is considerably higher (by a factor of about 20) for 
Sample2 in which an in-phase torsional load was superimposed on the axial cyclic loads. The duration of retardation, the distance that the crack advances during the transient behaviour after overload, was 0.385 and $0.275 \mathrm{~mm}$ which is corresponds to 41000 and 2550 cycles for Sample1 and Sample2 respectively (Fig. 5.b and $\mathrm{d}$ ).

The noticeable difference between the crack growth rate for Sample1 and Sample2 can be attributed to two
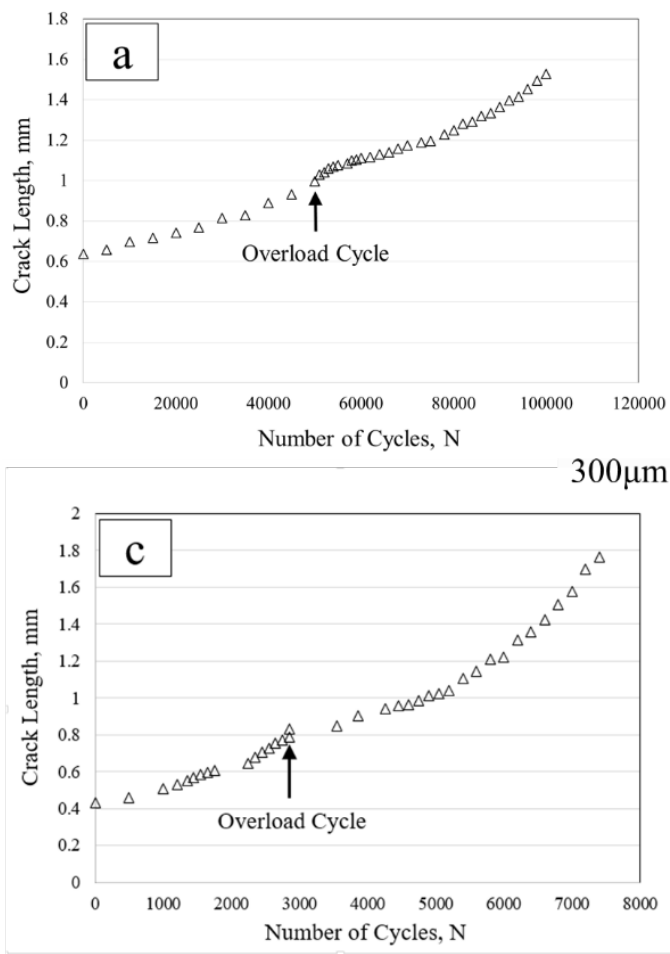

main difference between the applied loads. First, by calculating the principal stresses corresponds to the applied axial and torsional loads, it was observed that the principal stress value normal to the crack line $(\sigma 1)$ and consequently the equivalent von Mises stress ( $\sigma \mathrm{e})$ at the maximum axial load were 303 and $338 \mathrm{MPa}$ which is $26 \%$ and $40 \%$ higher than applied axial load in Sample 1 .
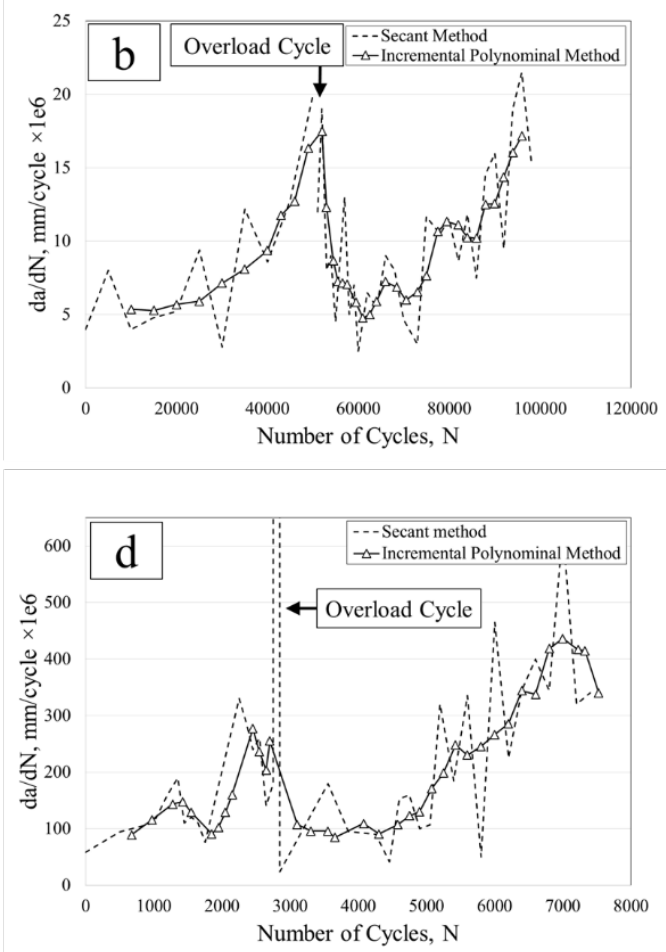

Fig. 5. Evolution of crack length and crack growth rate as a function of number of cycles for Sample 1 (a and b) and Smaple2 (c and d).

Although the stress amplitude $\left(\sigma_{\mathrm{a}}\right)$ was almost at the same scale as pure axial loading condition, the mean stress has been increased form $136 \mathrm{MPa}$ in Sample1 to $231 \mathrm{MPa}$ in Sample2. In addition, the orientation of the principal axis with respect to the loading axis $(\theta)$ is not fixed during a complete cycle. It is a witness of nonproportional loading. It is believed that non-proportional loading is generally more damaging than proportional loading [40]. Fig. 6 shows the variation of applied loads during two cycles for Sample2.

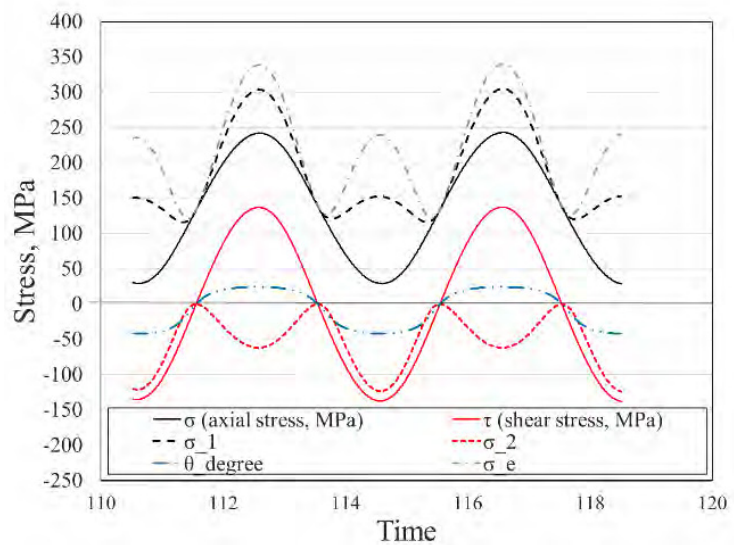

Fig. 6. Variation of nominal, principal and von Mises equivalent stresses during 2 complete cycles in Smaple2.

\subsection{COD Examination}

To determine the presence of crack closure, the displacement between two points at the top and bottom $\mathrm{pf}$ the crack line was monitored in different stages of the test (e.g. before and after overload cycle). All COD measurements were derived from the external surface of the specimen. Since the specimen thickness in the crack region was small $(2 \mathrm{~mm})$, no large differences are expected along the thickness [41]. Fig. 7 shows how the COD changes during a complete cycle for both samples. It can be seen that the loading and unloading path in Sample2 is considerably deviated from linear behaviour. In addition, right after overload cycle, the maximum value of COD for Sample2 has been reduced by $0.95 \mu \mathrm{m}$ $(18 \%)$, while it has been increase by a negligible value of $0.1 \mu \mathrm{m}$ for Sample1. On the other hand, from fig. 7.c and $d$, it can be observed that the slope of COD curve has been changed at lower portion of the graph by increasing the crack length for Sample1 which was under pure axial loading. This change in the slope often referred to as "knee" [42]. 
A compliance based method [43] was followed to quantify the opening load. Fig. 8 shows how opening load has been determined for Sample1. In Fig 8.b , COD-offset refers to the distance between the fitted least squares line at loads higher than $8 \mathrm{kN}$ (50\% of loading range) and the COD curve at each point. The estimated opening load for Sample1 at crack length of 1.03, 1.195 and $1.527 \mathrm{~mm}$ was $3.47,4.35$ and $4.62 \mathrm{kN}$, respectively.
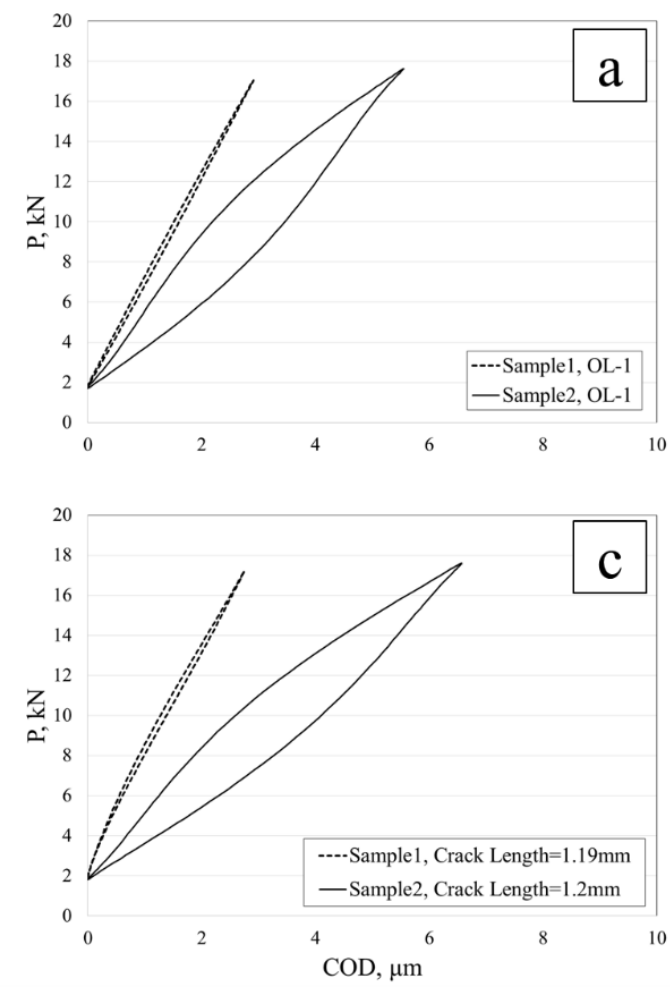

No closure was observed before and after overload cycle in Sample2.

\subsection{Experimental Evaluation of SIF by DIC}

DIC employed to extract the displacement field around the crack tip. Following the method described in [17,32], the stress intensity factor in mode I and mode II was determined experimentally.
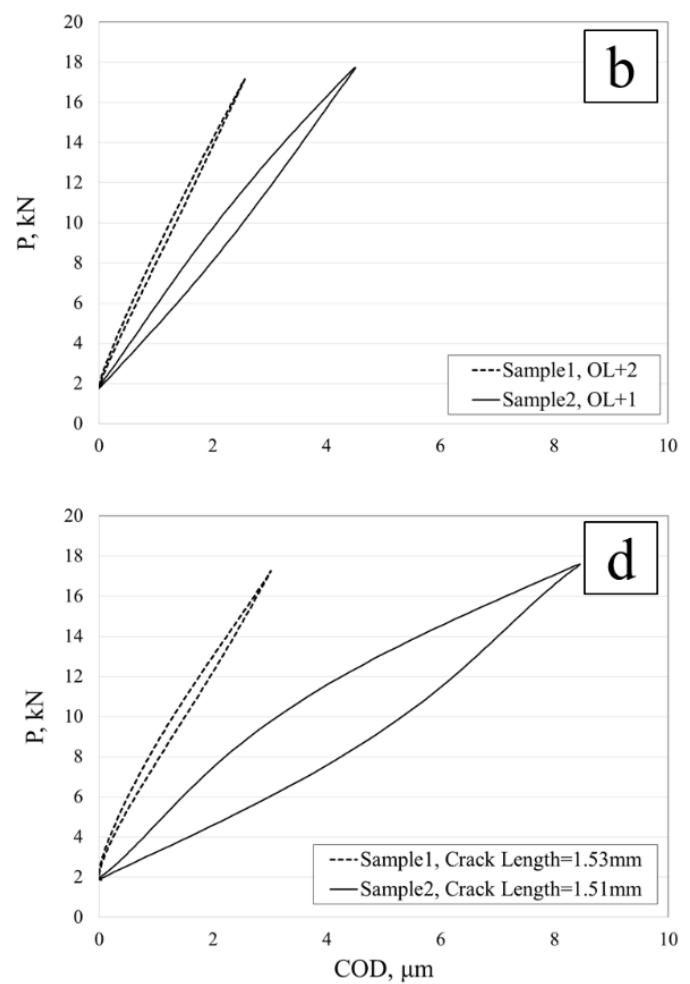

Figure 7. COD behaviour for Sample1 and Sample2 at different stages of loading (different crack lengths)

The method includes fitting the experimental displacement data to Williams' model using a multipoint over-deterministic method. Fig. 4 shows an example of the displacement field extracted from the surface of the Sample1. The experimental estimations of SIFs for Sample1 under uniaxial loading, were compared with the following theoretical solutions of SIF for a circular through crack in a cylinder as described in the AFGROW DTD handbook [44]:

$$
\Delta K_{\text {theo }}=F_{0} \sigma_{a} \sqrt{\pi a}
$$

where $F_{0}$ is the geometry factor, $\sigma_{a}$ is the nominal stress amplitude and $a$ is the crack length which is the sum of hole diameter and measured crack length from the crack initiation point at the circumference of the hole to the crack tip in both side of the hole. Effective stress intensity factor $\left(\Delta \mathrm{K}_{\text {eff }}\right)$ defined by considering the effective applied load $\left(\Delta \mathrm{P}_{\text {eff }}=\mathrm{P}_{\max }-\mathrm{P}_{\mathrm{op}}\right)$ in the SIF calculations. The results are summarized in Table 3.

A good agreement between $\Delta \mathrm{K}_{\text {exp }}$ and $\Delta \mathrm{K}_{\text {eff }}$ can be seen for crack length $(a)$ larger than $2 \mathrm{~mm}$. The poor experimental evaluation of SIF for short cracks can be attributed to the fact that for short cracks validation of Linear Elastic Fracture Mechanic (LEFM) is under question, while Williams' model is based on LEFM. It can also be seen that after applying the overload, $\Delta \mathrm{K}_{\text {eff }}$ has decreased from 17.6 to $15.4 \mathrm{MPa} \sqrt{\mathrm{m}}$ (about 12\%). Similar behaviour was also observed under uniaxial load [45]. It is interesting that both of $\Delta \mathrm{K}_{\exp }$ and $\Delta \mathrm{K}_{\text {eff }}$ are slightly smaller after 20,000 cycles after overload cycle. It should be mentioned that the difference between reported values is very little which is inside the error bands of the evaluated $\Delta \mathrm{K}_{\exp }( \pm 0.5 \mathrm{MPa} \sqrt{\mathrm{m}})$. As it is expected from uniaxial loading, the estimated value for $\Delta \mathrm{K}_{\mathrm{II}}$ was negligible.

With respect to Sample2, only the experimental evaluation of $\Delta \mathrm{K}_{\mathrm{I}}$ and $\Delta \mathrm{K}_{\mathrm{II}}$ are reported (Table 4) due to the lack of proper analytical method for evaluation of the SIF for the geometry and loading condition of the sample. It can be seen that right after overload cycle $\Delta K_{I}$ and $\Delta \mathrm{K}_{\mathrm{II}}$ decreased by 7.8 and $6.6 \mathrm{MPa} \sqrt{\mathrm{m}}$. Moreover, $\Delta \mathrm{K}_{\mathrm{Iexp}}$ for Sample2 was more than two times higher than thereof for Sample1. This can justify higher crack growth rate under biaxial loaded sample rather pure axial loaded one.

Table 3. Comparison between evaluated $\Delta \mathrm{KI}$ by theoretical and experimental methods for Sample1. 


\begin{tabular}{|l|c|c|c|c|c|c|}
\cline { 2 - 7 } \multicolumn{1}{c|}{} & \multicolumn{1}{c|}{$a, \mathrm{~mm}$} & $\Delta \mathrm{P}, \mathrm{N}$ & $\Delta \sigma, \mathrm{MPa}$ & $\Delta \mathrm{K}_{\text {theo }}$ & $\Delta \mathrm{K}_{\text {eff }}$ & $\Delta \mathrm{K}_{\text {exp }}$ \\
\hline OL-50kCycle & 1.28 & 15718 & 221 & 17.6 & 17.6 & 11.3 \\
OL-1Cycle & 1.99 & 15261 & 220 & 17.6 & 17.6 & 15.0 \\
OL+2Cycle & 2.06 & 15254 & 220 & 17.7 & 15.4 & 15.7 \\
OL+25kCycle & 2.39 & 15347 & 223 & 18.0 & 15.2 & 15.5 \\
OL+50kCycle & 3.05 & 15425 & 228 & 18.7 & 15.3 & 16.9 \\
\hline
\end{tabular}
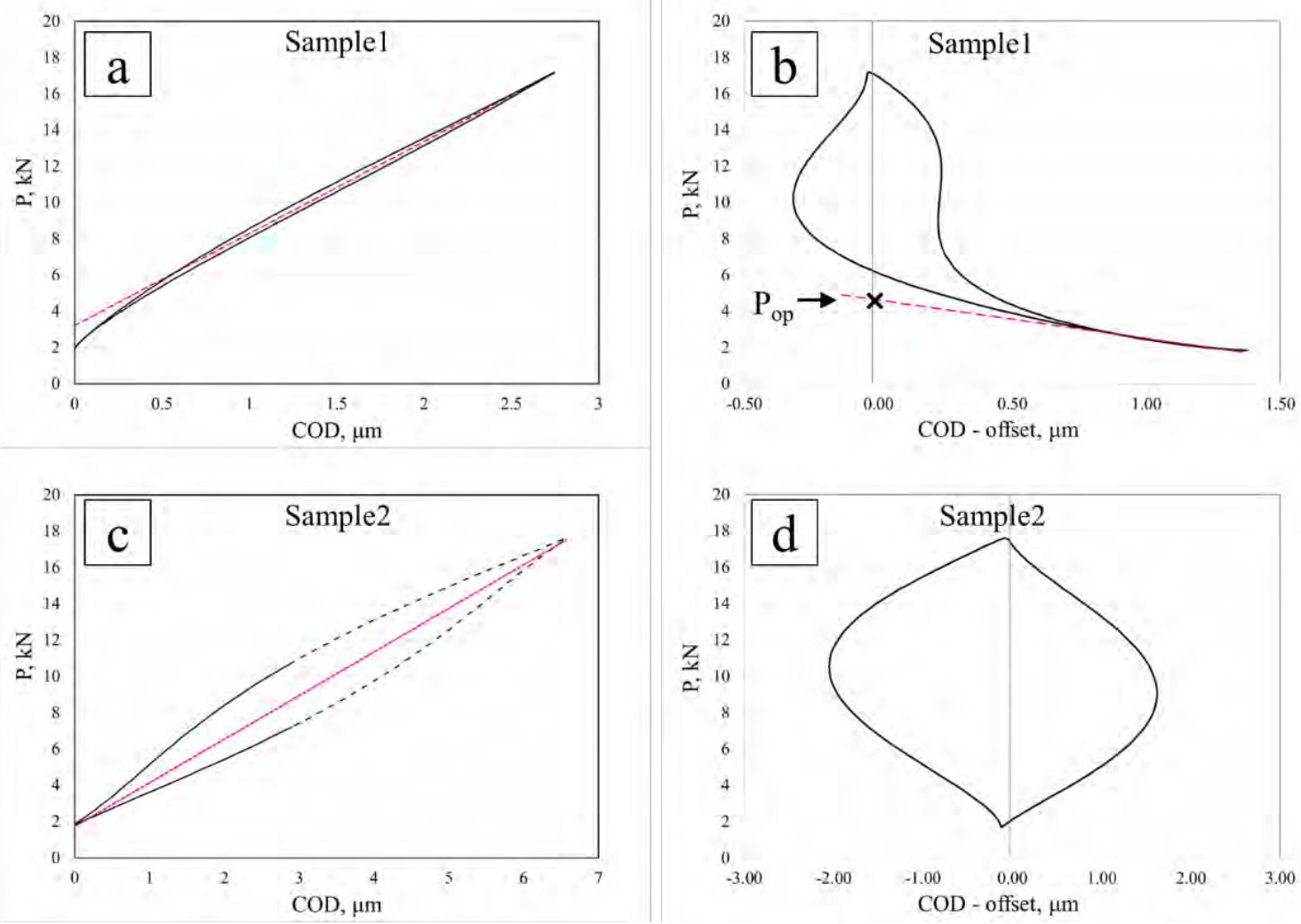

Fig. 8. Evaluation of opening load for Sample1 and Sample2 after overload at crack length of 1.195 and 1.209 mm, respectively.

\section{Conclusion}

An investigation on the effect of overload cycle of $40 \%$ on the crack growth rate for uniaxial and biaxial loading was conducted by employing an optical - analytical method. It was observed that the crack growth rate increased by a factor of about 20 by superimposing an in-phase torsional load in Sample2. COD examinations also showed higher values for Sample2 under biaxial load. Crack closure was observed immediate after overload cycle for pure axial loaded sample, while no closure was detected for sample under biaxial loads. A hybrid method including extracting full-field displacement data by DIC and fitting it to the analytical solution of Williams' were used to evaluate the experimental SIFs. A good agreement between experimental and theoretical solution for SIF was achieved.

Acknowledgements. Financial support of Ministerio de Economia y Competitividad through grant reference MAT2016-76951-C2-2-P is greatly acknowledged.; and the University of Malaga through Campus de Excelencia
Internacional del Mar (CEIMAR) through Líneas Emergentes program and for providing $\mathrm{PhD}$ scholarship is greatly acknowledged.

\section{References}

[1] Irwin GR. Analysis of stresses and strains near the end of a crack traversing a plate. J Appl Mech ASME 1957;E24:351-69.

[2] Anderson TL. Fracture Mechanics Fundamentals and Applications. 2nd Ed. CRC Press; (1995).

[3] Paris PP, Erdogan FF. A Critical Analysis of Crack Propagation Laws. ASME J Basic Eng (1963);85:52833.

[4] Sutton MA, Orteu J-J, Schreier HW. Image correlation for shape, motion and deformation measurements. New York: Springer; (2009).

[5] de Matos PFP, Nowell D. Numerical simulation of plasticity-induced fatigue crack closure with emphasis on the crack growth scheme: 2D and 3D analyses. Eng Fract Mech (2008);75:2087-114.

[6] Nowell D, Paynter RJH, De Matos PFP. Optical methods for measurement of fatigue crack closure: moiré 
interferometry and digital image correlation. Fatigue Fract Eng Mater Struct (2010);33:778-90.

[7] Westergaard HM. Bearing pressures and cracks. J Appl Mech (1939);61:A49-53.

[8] Williams ML. On the stress distribution at the base of a stationary crack. J Appl Mech (1957);24:109-14.

[9] Christopher CJ, James MN, Patterson EA, Tee KF. Towards a new model of crack tip stress fields. Int $\mathrm{J}$ Fract (2007);148:361-71.

[10] Ramesh K, Gupta S, Kelkar AA. Evaluation of stress field parameters in fracture mechanics by photoelasticity - revisited. Eng Fract Mech (1997);56:2541-45.

[11] Díaz FA, Yates JR, Patterson EA. Some improvements in the analysis of fatigue cracks using thermoelasticity. Int J Fatigue (2004);26:365-76.

[12] McNeill SR, Peters WH, Sutton MA. Estimation of stress intensity factor by digital image correlation. Eng Fract Mech (1987);28:101-12.

[13] Yoneyama S, Kitagawa A, Iwata S, Tani K, Kikuta H. Bridge deflection measurement using digital image correlation. Exp Tech (2007);31:34-40.

[14] Sutton MA, Li N, Joy DC, Reynolds AP, Li X. Scanning electron microscopy for quantitative small and large deformation measurements Part I: SEM imaging at magnifications from 200 to 10,000. Exp Mech (2007);47:775-87.

[15] Carroll JD, Abuzaid W, Lambros J, Sehitoglu H. High resolution digital image correlation measurements of strain accumulation in fatigue crack growth. Int $\mathrm{J}$ Fatigue (2013);57:140-50.

[16] Sanford RJ, Dally JW. A general method for determining mixed-mode stress intensity factors from isochromatic fringe patterns. Eng Fract Mech (1979);11:621-33.

[17] Yates JR, Zanganeh M, Tai YH. Quantifying crack tip displacement fields with DIC. Eng Fract Mech (2010);77:2063-76.

[18] Hamam R, Hild F, Roux S. Stress intensity factor gauging by digital image correlation: Application in cyclic fatigue. Strain (2007);43:181-92.

[19] Roux S, Hild F. Stress intensity factor measurements from digital image correlation: postprocessing and integrated approaches. Int $\mathrm{J}$ Fract (2006);140:141-57.

[20] Qian J, Fatemi A. Mixed mode fatigue crack growth: A literature survey. Eng Fract Mech (1996);55:969-90.

[21] Socie D, Marquis, Gary. Multiaxial Fatigue. SAE International; (1999).

[22] Yoneyama S, Ogawa T, Kobayashi Y. Evaluating mixed-mode stress intensity factors from full-field displacement fields obtained by optical methods. Eng Fract Mech (2007); 74:1399-412.

[23] Réthoré J, Gravouil a., Morestin F, Combescure a. Estimation of mixed-mode stress intensity factors using digital image correlation and an interaction integral. Int $\mathbf{J}$ Fract (2005);132:65-79.

[24] López-Crespo P, Burguete RL, Patterson EA, Shterenlikht A, Withers PJ, Yates JR. Study of a crack at a fastener hole by digital image correlation. Exp Mech (2009);49:551-9.

[25] Carlson RL, Kardomateas GA, Bates PR. The effects of overloads in fatigue crack growth. Int J Fatigue (1991);13:453-60.

[26] Salvati E, O'Connor S, Sui T, Nowell D, Korsunsky AM. A study of overload effect on fatigue crack propagation using EBSD, FIB-DIC and FEM methods. Eng Fract Mech (2015);167:1-14.

[27] de Matos PFP, Nowell D. Experimental and numerical investigation of thickness effects in plasticityinduced fatigue crack closure. Int $\mathrm{J}$ Fatigue (2009);31:1795-804.

[28] Yusof F, Lopez-Crespo P, Withers PJ. Effect of overload on crack closure in thick and thin specimens via digital image correlation. Int J Fatigue (2013);56:1724.

[29] Sander M, Richard H. Experimental and numerical investigations on the influence of the loading direction on the fatigue crack growth. Int $\mathrm{J}$ Fatigue (2006);28:583-91.

[30] Sander M, Richard HA. Finite element analysis of fatigue crack growth with interspersed mode I and mixed mode overloads. Int J Fatigue (2005);27:905-13.

[31] Srinivas V, Vasudevan P. Study of the influence of mixed mode overload on mode I fatigue crack propagation. Int J Press Vessel Pip (1993);56:409-17.

[32] Mokhtarishirazabad M, Lopez-Crespo P, Moreno B, Lopez-Moreno A, Zanganeh M. Optical and analytical investigation of overloads in biaxial fatigue cracks. Int J Fatigue (2017);100:583-90.

[33] Chaves V. Ecological criteria for the selection of materials in fatigue. Fatigue Fract Eng Mater Struct (2014);37:1034-42.

[34] Lopez-Crespo P, Moreno B, Lopez-Moreno A, Zapatero J. Study of crack orientation and fatigue life prediction in biaxial fatigue with critical plane models. Eng Fract Mech (2015);136:115-30.

[35] ASTM E647-15, Standard Test Method for Measurement of Fatigue Crack Growth Rates. West Conshohocken, PA: (2015).

[36] Lopez-Crespo P, Moreno B, Lopez-Moreno A, Zapatero J. Characterisation of crack-tip fields in biaxial fatigue based on high-magnification image correlation and electro-spray technique. Int J Fatigue (2015);71:1725.

[37] Zanganeh M, Lopez-Crespo P, Tai YH, Yates JR. Locating the crack tip using displacement field data: a comparative study. Strain (2013);49:102-15.

[38] Vic-2D V6 Reference Manual, Correlated Solutions Incorporated (C.S.Inc).

[39] Mokhtarishirazabad M, Lopez-Crespo P, Moreno B, Lopez-Moreno A, Zanganeh M. Evaluation of cracktip fields from DIC data: A parametric study. Int J Fatigue (2016);89:11-9.

[40] S. Suresh. Fatigue of Materials. 2nd ed. New York: Cambridge University Press; (1998).

[41] Withers PJ, Lopez-Crespo P, Kyrieleis a., Hung Y-C. Evolution of crack-bridging and crack-tip driving force during the growth of a fatigue crack in a $\mathrm{Ti} / \mathrm{SiC}$ composite. Proc R Soc A Math Phys Eng Sci (2012);468:2722-43. 
[42] Joyce JA, Sutton GE. An automated method of computered-controlled low-cycle fatigue crack growth testing using the eslastic-plastic parameter cyclic J. In: Cullen WH, Landgraf RW, Kaizand LR, Underwood JH, editors. Autom. test methods Fract. fatigue crack growth, American Society for Testing and Materials; (1985), 225-47.

[43] Skorupa M, Beretta S, Carboni M, Machniewicz T. An algorithm for evaluating crack closure from local compliance measurements. Fatigue Fract Eng Mater Struct (2002);25:261-73.

[44] DTD AFGROW Handbook. n.d.

[45] Lopez-Crespo P, Mostafavi M, Steuwer A, Kelleher JF, Buslaps T, Withers PJ. Characterisation of overloads in fatigue by $2 \mathrm{D}$ strain mapping at the surface and in the bulk. Fatigue Fract Eng Mater Struct (2016);39:1040-8. 